Journal of Advanced Research in Fluid Mechanics and Thermal Sciences

Journal homepage: www.akademiabaru.com/arfmts.html ISSN: $2289-7879$

\title{
CFD Study on Thermal Implication towards Human Body in Office Environment
}

\author{
Ahmad Rasdan Ismail ${ }^{1,2,}{ }^{*}$, Norfadzilah Jusoh², Nor Kamilah Makhtar ${ }^{3}$, Nor Kamaliana Khamis ${ }^{4}$, \\ Raemy Md Zein ${ }^{5}$, Nurul Husna Che Hassan ${ }^{1}$ \\ 1 Centre for Management of Environment, Occupational Safety and Health (CMeOSH), Universiti Malaysia Kelantan, 16300 Bachok, Kelantan, \\ Malaysia \\ 2 Faculty of Creative Technology \& Heritage, Universiti Malaysia Kelantan, 16300 Bachok, Kelantan, Malaysia \\ 3 Department of Research and Innovation Planning, Institute of Teacher Education, Kota Bharu, Kelantan, Malaysia \\ 4 Department of Mechanical and Manufacturing Engineering, Faculty of Engineering and Built Environment, Universiti Kebangsaan Malaysia, \\ 43600, Bandar Baru Bangi, Selangor, Malaysia \\ 5 National Institute of Occupational Safety and Health (NIOSH), 43650 Bandar Baru Bangi, Selangor, Malaysia
}

\section{ARTICLE INFO}

Article history:

Received 11 April 2021

Received in revised form 20 June 2021

Accepted 25 June 2021

Available online 1 August 2021

\section{Keywords:}

Thermal comfort; PMV; temperature; CFD

\section{ABSTRACT}

\section{Introduction}

Complaints about air-conditioning in offices are very common - it is either too hot or too cold. The temperature varies drastically through the day. The draughts are terrible. It is not only the temperature that affects how people feel, but also the humidity levels, air movement and people and electronics surrounding that's means increasing heat in the space.

\footnotetext{
* Corresponding author.

E-mail address: rasdan@umk.edu.my

https://doi.org/10.37934/arfmts.85.1.125134
} 
Thermal comfort is the occupants' satisfaction with the surrounding thermal conditions. It can only be maintained when the heat produced by metabolism equals the heat loss from the body. It is must be environmentally friendly [1]. However, thermal comfort is difficult to measure because it is highly subjective. Each experiences sensations a bit differently based on their physiology and state. Moreover, the temperature of the skin is not consistent with all areas of the body [2]. There are variations in different parts of the body which reflect the differences in blood flow and subcutaneous fat. Additionally, the indoor thermal sensation within the same building could deviate significantly because of different room orientations, facade designs or effects of buildings in the neighbourhood [3].

Hensen [4] explained that thermal comfort condition is occasionally identified as a state in which there are no driving impulses to correct the environment by behaviour. Djongyang et al., [5] pointed out it will be influenced by personal differences in mood, culture and other individual organizational and social factor. There were studies reported that emphasized the judgment of comfort is a cognitive process involving many inputs influenced by physical, physiological and psychological [6]. Cena and Clark [7] reviewed their categories of science that influenced the thermal comfort, namely

i. Physics: How human regulates the thermal environment, including clothing

ii. Physiology: The mechanisms of thermoregulation and acclimatization and their variation with age and health

iii. Psychology: The perception of comfort and discomfort and its relation to other competing stimuli

In order to evaluate the thermal comfort, a subjective and comprehensive index, Predicted Mean Index Vote (PMV) proposed by Fanger is used to quantitatively assess the thermal sensation of occupants by combining the environmental factors with human factors [8]. The PMV means the expected mean value of the thermal sensation votes of a large group of occupants in a sensation scale expressed from -3 to +3 corresponding to the categories 'cold', 'cool', 'slightly cool', neutral', 'slightly warm', 'warm', and 'hot' as illustrated in Table 1 [9]. Fanger [8] developed the Predicted Percentage of Dissatisfied (PPD), a method used to estimate unacceptable conditions for occupants. According to the PPD method, if $95 \%$ of the occupants in the building are satisfied, then the environment is classified as comfortable. However, PPD is based on PMV, which is used to predict an occupant's thermal sensation followed by the environmental parameters. Therefore, the PMV must be calculated first to obtain PPD.

There are six necessary environmental parameters to calculate PMV values, as shown in Figure 1, such as air temperature, air velocity, radiant temperature, relative humidity, metabolic rate and clothing insulation.

Parsons [10] defined air temperature $\left(T_{a}\right)$ is a measurement that determines how cold or hot the air is. More specifically, temperature describes the kinetic energy or energy motion of the gases that make up air. As gas molecules move more quickly, air temperature increases. Alternatively, Ta is the dry bulb temperature, which is the most significant factor in determining the energy balance, comfort, discomfort, thermal sensation and perception of air quality. It can be measured by mercury in glass thermometer shielded from direct heat radiation and suspended in the air [11].

The ISO 7726 [12] defines the radiant temperature is the uniform temperature of an imaginary enclosure in which radiant heat transfer from the human body is equal to the radiant heat transfer in the actual non-uniform enclosure. Furthermore, the radiant temperature of the human body can be calculated from the warmth of surrounding surfaces and their orientation concerning the human body. 
Air velocity is defined in [13] as the average speed of the air to which the body is exposed, with respect to the location and time. The human body is very sensitive with air movement, especially in some parts like the neck, the head and the feet, and it also depends on the person's sensitivity. If the flow rate is too high or irregular, then local thermal discomfort appears. Thus, it is essential to easily control the air velocity and the flow direction [14].

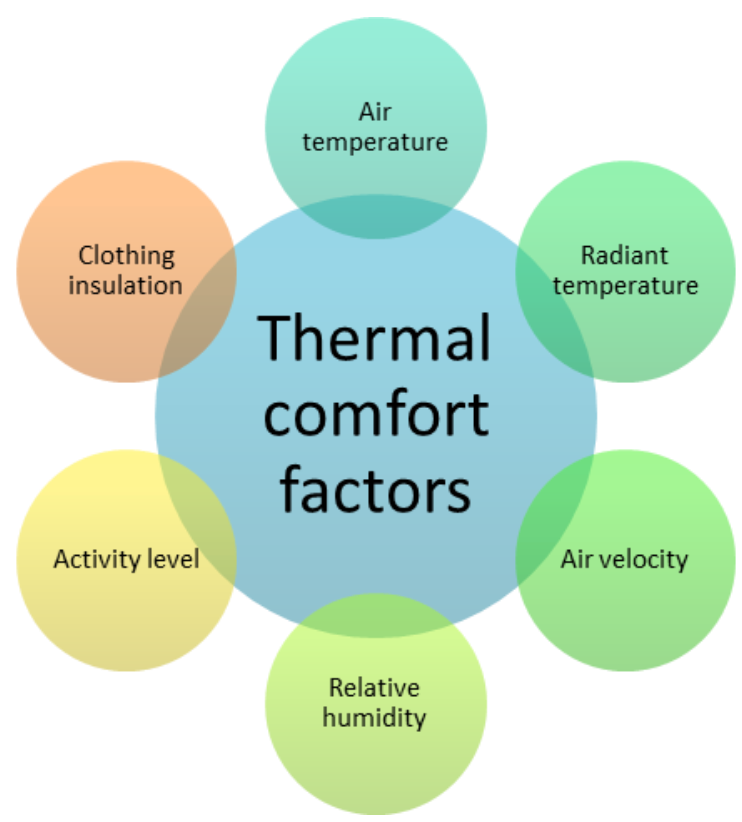

Fig. 1. Thermal comfort factors

Table 1

Standard thermal sensation scale

\begin{tabular}{ll}
\hline Thermal Sensation & Vote Number (PMV) \\
\hline Hot & +3 \\
Warm & +2 \\
Slightly Warm & +1 \\
Neutral & 0 \\
Slightly Cool & -1 \\
Cool & -2 \\
Cold & -3 \\
\hline
\end{tabular}

Typically, there are two approaches available for investigation of the indoor environment which is Computational Fluid Dynamics (CFD) simulation and experimental investigation [15][16]. In principle, the direct experiment can get the most realistic information of the environmental parameters, such as air temperature, air velocity, relative humidity and contaminant concentrations at limited interested locations. However, the measurement is always with high expenses to get all spatial airflow data and time-consuming to install the measurement devices. Ismail and Che Jamil [17] used CFD to predict the temperature and the air velocity behaviors in the building. CFD simulations can economically obtain airflow patterns and thermal environment for further evaluation of indoor thermal comfort. Therefore, the objective of this study is to evaluate the thermal environmental conditions of air conditioning with CFD simulations. 


\section{Methodology}

A designated chamber was developed specifically for the purpose of this study where the subjects were exposed to a different temperature. Meanwhile, thermal comfort votes were collected from the subjects. Details of methodology are explained in the following subsections.

\subsection{Environmental Chamber}

This study was designed to control conditions of the laboratory studies. To achieve this model, office environment has been built in an environmental chamber. The experiments were carried out at the Workplaces Ergonomic Simulator Chamber (WES-103) in Universiti Malaysia Pahang, Malaysia. Before the beginning of the experiment, a calibration study was done to equate the results of the Ergonomic Simulator Chamber used. The calibration was conducted for the purpose of checking for precision in other to confirm their degree of accuracy [18]. Figure 2 shows the model of the office room in an environmental chamber. For this study, the York Prestige Ceiling type of air conditioner was used to explore the environment climate in the chamber. This model is ideally suited for use in the hot climate in Pahang. The dimension of this air conditioner is $21.8 \mathrm{~cm} \times 108 \mathrm{~cm} \times 63 \mathrm{~cm}$. The material of the environmental chamber is Polyurethane insulated panels. Table 2 presented the details of the specification of the climate chamber.

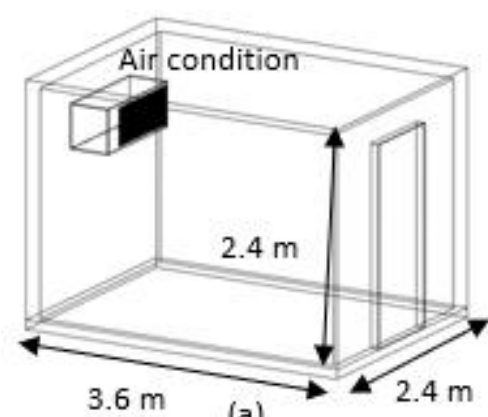

(a)

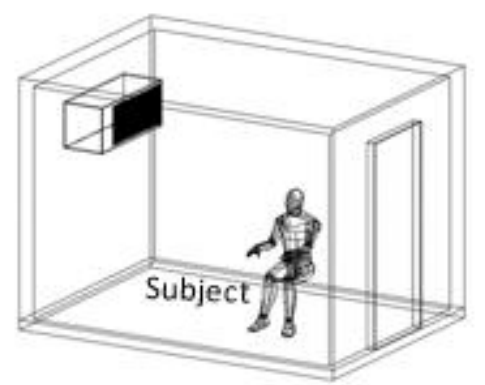

(b)

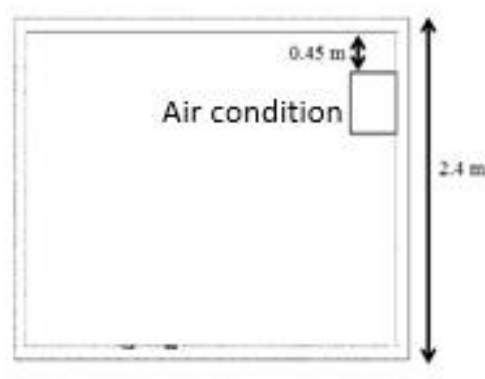

(c)

Fig. 2. The layout of the environmental chamber: (a) Environmental chamber without subject, (b) Environmental chamber with subject and (c) Environmental chamber from side view

Table 2

Specification of environmental chamber

\begin{tabular}{ll}
\hline Property & Result \\
\hline Density & $40-45 \mathrm{~kg} / \mathrm{m}^{3}$ \\
Thermal conductivity & $0.017 \mathrm{~W} / \mathrm{mK}$ \\
Compressive strength & $180-250 \mathrm{kPa}$ \\
Thermal coefficient & $0.239-0.151 \mathrm{~W} /(\mathrm{mK})$ \\
Operating temperature & -68 to $121^{\circ} \mathrm{C}$ \\
\hline
\end{tabular}

Thermal comfort tests with human subjects were conducted to test the thermal comfort and thermal sensation of human for various thermal conditions. Fifteen volunteers (eight males and seven female) were recruited in this study. The number of subjects in the study was agreed by Goldman [19]. Goldman has 50 years' experience in the field of human thermal comfort and state that the minimum subject for the study of human comfort is as many as six people. 
All fifteen subjects were used in this study to measure thermal comfort and productivity while doing multitask in the chamber (represent an office room). There are three tasks the subjects must follow, such as relaxing while sitting, typing or writing and printing paperwork, as shown as in Table 3.

\begin{tabular}{|c|c|c|}
\hline No & Types of the task & Metabolic rate (Met) \\
\hline 1 & Thinking & 1.0 \\
\hline 2 & Sitting while typing & 1.2 \\
\hline 3 & Printing & 1.6 \\
\hline
\end{tabular}

The steps and duration of experiment were shown in Table 4. The subjects entered the chamber and spent $10 \mathrm{~min}$ in the chamber before the test acclimatizes with the room temperature [20-22]. All the three tasks of activities during which the subjects were exposed to multiple thermal conditions. All tasks which are explained in Table 4 were repeated with three temperature setting of air conditioning $\left(21^{\circ} \mathrm{C}, 23^{\circ} \mathrm{C}\right.$ and $\left.26^{\circ} \mathrm{C}\right)$. The actual test had three tasks and lasted for three hours 20 min with two breaks.

Thermal conditions of this range from sedentary activity and neutral room temperatures to high metabolic activity and high room temperatures which fall clearly outside the comfort zone based on ASHRAE Standard 55 [13]. One of the premises of this study is that thermal comfort is a psychological phenomenon and can be achieved even the physical conditions suggest otherwise.

Table 4

Steps and duration of the experiment

\begin{tabular}{lll}
\hline Step & Activity & Duration (min) \\
\hline 1 & Measured demographics of subjects & 30 \\
2 & Standby in a waiting room & 10 \\
3 & Start the measurement with Task $1\left(21,23\right.$ and $\left.26^{\circ} \mathrm{C}\right)$ & $10 \times 5=50$ \\
4 & Break & 5 \\
5 & Task 2 $\left(21,23\right.$ and $\left.26^{\circ} \mathrm{C}\right)$ & $10 \times 5=50$ \\
6 & Break & 5 \\
7 & Task $3\left(21,23\right.$ and $\left.26^{\circ} \mathrm{C}\right)$ & $10 \times 5=50$ \\
& Total & 200 \\
\hline
\end{tabular}

\subsection{Computational Fluid Dynamics (CFD)}

In this study, the comfort parameter of the room is influenced by the air-conditioner temperature. Thus, CFD is performed to predict the results of comfort parameter's distribution of environment and thermal parameters of the human manikin at different from the air-conditioner output temperature. Table 5 listed the initial conditions that are included in the CFD environment for the flow analysis.

After the setup, the components will be generated in the computational domain. It constructed the mesh at various refinements for the elements, and the model is ready for simulations. The same setup is used to compare the environment with and without the presence of the human manikin. 


\section{Table 5}

Initial conditions of flow simulation

\begin{tabular}{lll}
\hline Parameter & Surface/Components & Value \\
\hline$T_{\text {wall, }}$ & Wall 1, Wall 2 & $24.5^{\circ} \mathrm{C}$ \\
$T_{\text {wall, }}$ & Wall 3, Wall 4, Door & $23.5^{\circ} \mathrm{C}$ \\
$T_{\text {wall,3 }}$ & Ceiling, Floor & $24.5^{\circ} \mathrm{C}$ \\
$T_{\text {fan }}$ & Inlet air-conditioning & $21,23,26^{\circ} \mathrm{C}$ \\
$T_{\text {environment }}$ & Surrounding & $27{ }^{\circ} \mathrm{C}$ \\
$P_{\text {environment }}$ & Surrounding & $101325 \mathrm{~Pa}$ \\
$Q_{\text {manikin }}$ & Manikin & $144 \mathrm{~W}$ \\
$R H$ & Surrounding & $70 \%$ \\
Gravity & X & $0 \mathrm{~m} / \mathrm{s}^{2}$ \\
& Y & $-9.81 \mathrm{~m} / \mathrm{s}^{2}$ \\
& Z & $0 \mathrm{~m} / \mathrm{s}^{2}$ \\
Fluid type & Air & Laminar and turbulent \\
\hline
\end{tabular}

\section{Results}

The importance of air conditioning is to ensure the rationality of indoor air distribution because it is closely related to the effect of adjusting indoor temperature, air conditioning energy consumption, human body comfort and health status. The rationality of the airflow in a room with air conditioning not only influences indoor air adjustment but also directly affects the air conditioning system. Furthermore, it determines the impact of indoor air quality on human health. Therefore, the reasonable indoor air distribution must meet the requirements of energy saving, comfortable and healthy.

Heat transfer inside the human body is calculated for a given level of activity (metabolic rate), using the two node human thermoregulation model. Prediction of metabolic heat dispersal to the surroundings is accomplished by a CFD code. Results for different cases with varying supply air velocity, temperature and radiant temperature as well as the human metabolic rate are obtained to predict thermal comfort conditions in the room, using several comfort indices.

Results are obtained in empty (Table 6) and occupied room (Table 7) cases to show the effect of human occupation in a ventilated room on parameters such as radiant temperature $\left(T_{r}\right)$, air temperature $\left(T_{a}\right)$, air velocity $\left(v_{a}\right)$, PMV and PPD indices. All results are presented in side view as, illustrated in Table 6 and 7.

Table 6 and 7 show the results air temperature of non-occupied and occupied at different operative temperatures. The results of air temperature in this study showed that they are not significantly different, non-occupied and occupied. Table 6 and 7 also indicates that the higher the supply air temperature, the faster the air temperature rises.

Radiant effects commonly sensed by the occupants of offices occur. The presence of a strong thermal radiant field can also become a serious issue in the context of productivity. In many offices, due to limited space or other reasons, two or more people can occupy the same relatively small room. Imagine the situation where the one sitting near the wall or window with a strong, radiant field is the one who prefers to be on the cooler side of thermal sensation and the one sitting near the inner wall prefers the warmer side of thermal sensation. In such a situation, different thermal preferences due to the presence of radiant asymmetry can create thermal comfort tension. In general, the radiant temperature was related to the human body surface. In this study, the radiant temperature comparatively higher in the occupied space compares to the non-occupied space. 
The air velocity is one of the essential parameters for the human thermal comfort; an increased air velocity will aid the evaporation of sweat thus leading to a cooling effect, mainly if loose clothing is worn [23]. However, if the air velocity is too high, it may cause discomfort and a sensation of draughtiness. Table 6 and 7 shows a comparison of air velocity at each supply air temperature between non-occupied and occupied space. It shows that supply air temperature at $21{ }^{\circ} \mathrm{C}, 2{ }^{\circ} \mathrm{C}$ and $26{ }^{\circ} \mathrm{C}$ for non-occupied is higher than the occupied space, which are $0.16 \mathrm{~m} / \mathrm{s}, 0.22 \mathrm{~m} / \mathrm{s}$ and $0.08 \mathrm{~m} / \mathrm{s}$ respectively.

\section{Table 6}

Results CFD for empty room

\begin{tabular}{llll}
\hline Operative & 21 & 23 & 26
\end{tabular}

temperature,

$\mathrm{T}_{\mathrm{o}}\left({ }^{\circ} \mathrm{C}\right)$

Air

temperature,

$\mathrm{T}_{\mathrm{a}}\left({ }^{\circ} \mathrm{C}\right)$

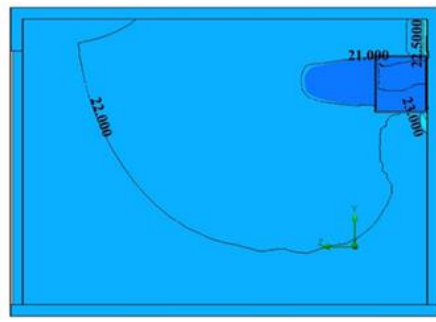

Radiant temperature, $\operatorname{Tr}\left({ }^{\circ} \mathrm{C}\right)$

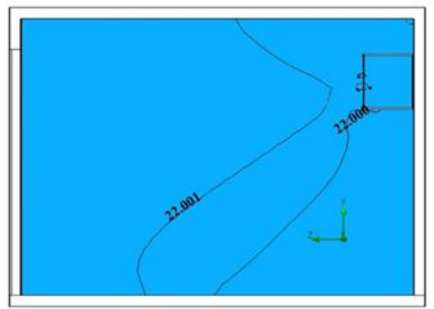

Air velocity, (va)

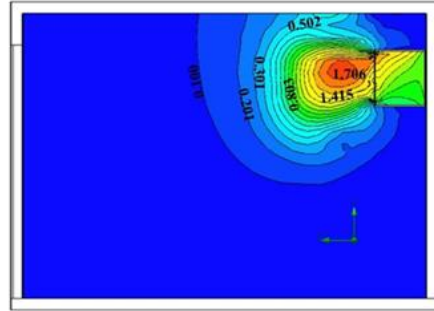

PMV

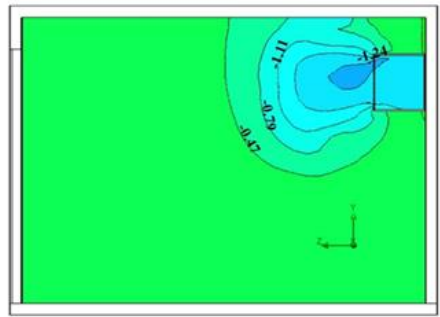

PPD

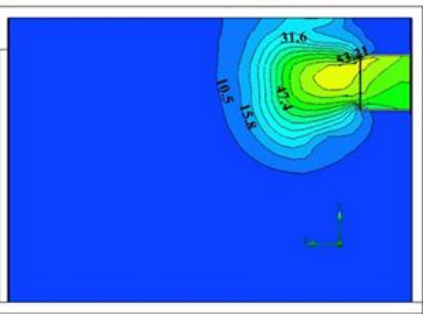

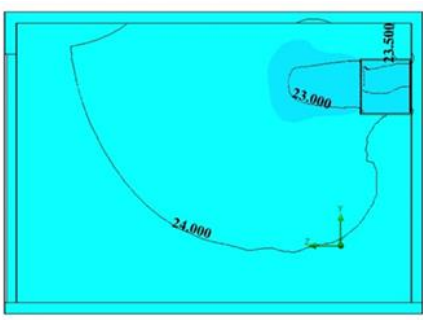
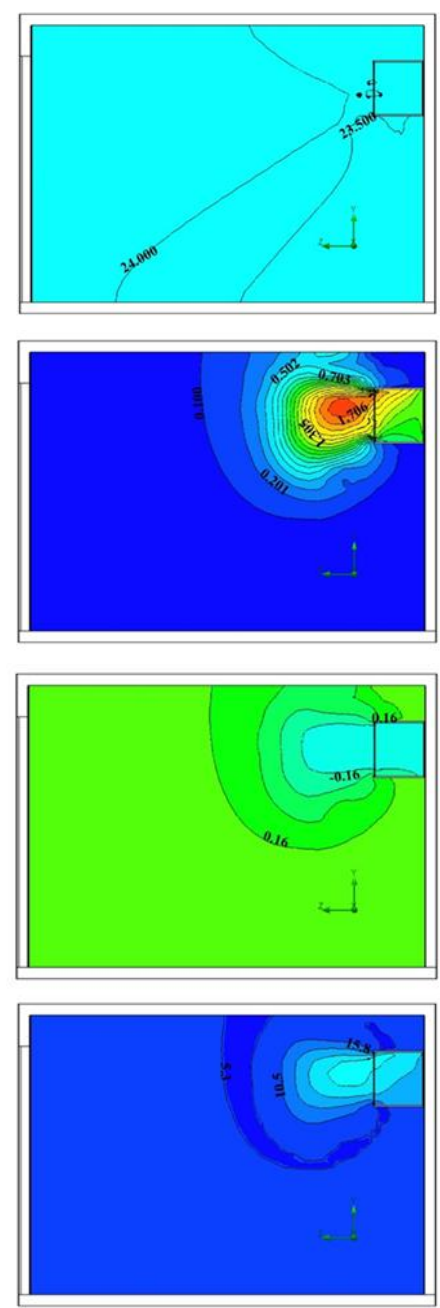
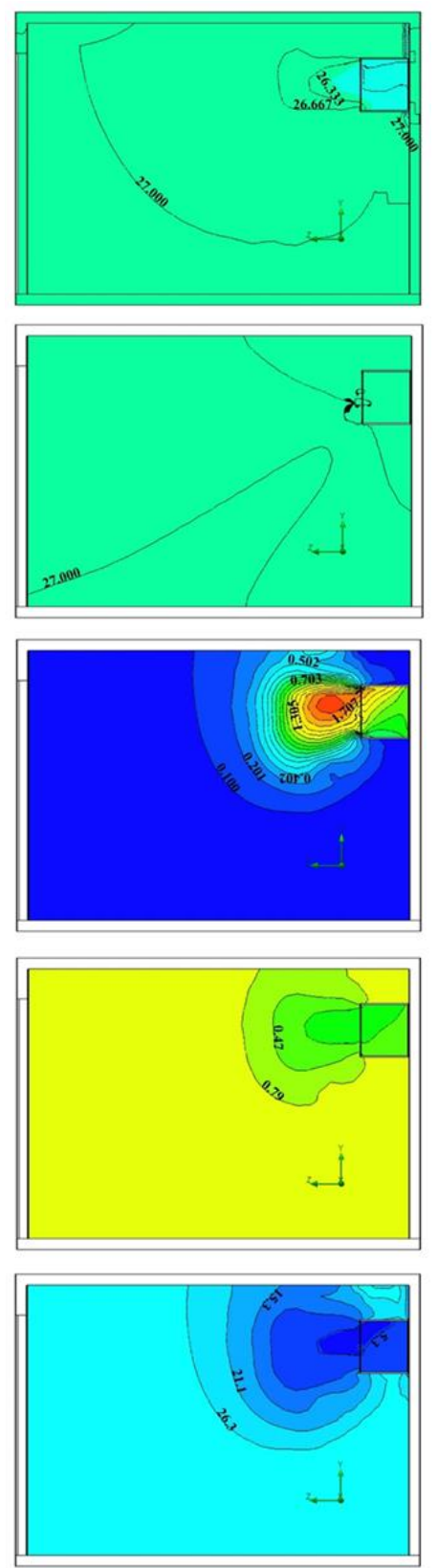
Table 7

Results CFD for occupied room

$\begin{array}{llll}\text { Operative } 21 & 23 & 26\end{array}$

temperature,

$\mathrm{T}_{0}\left({ }^{\circ} \mathrm{C}\right)$

Air

temperature,

$\mathrm{Ta}\left({ }^{\circ} \mathrm{C}\right)$
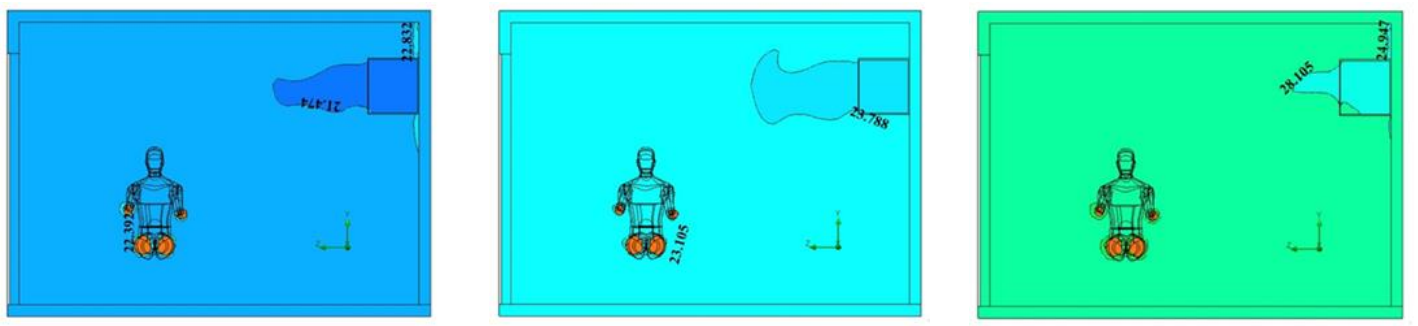

Radiant temperature, $\operatorname{Tr}\left({ }^{\circ} \mathrm{C}\right)$
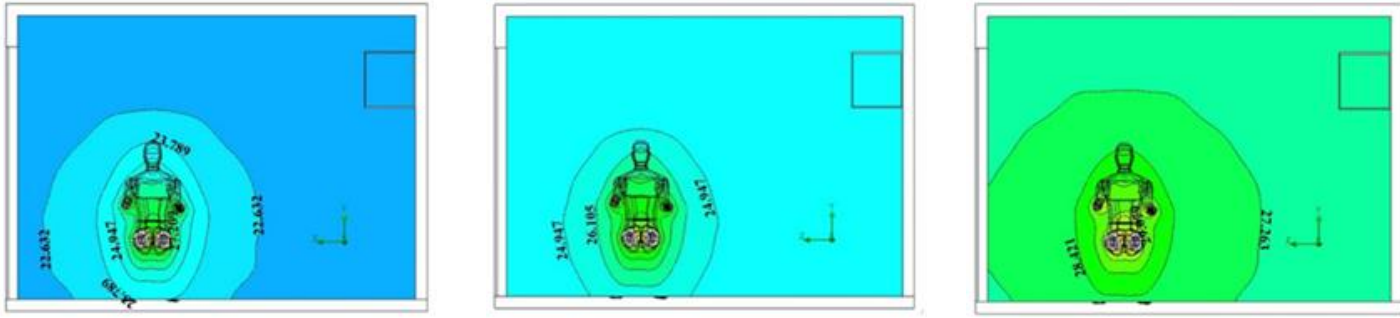

Air velocity, $\left(v_{a}\right)$
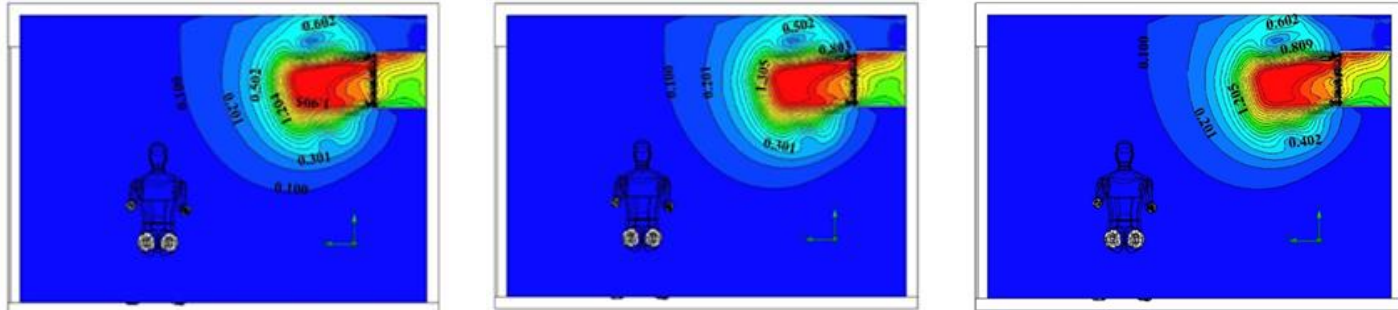

PMV
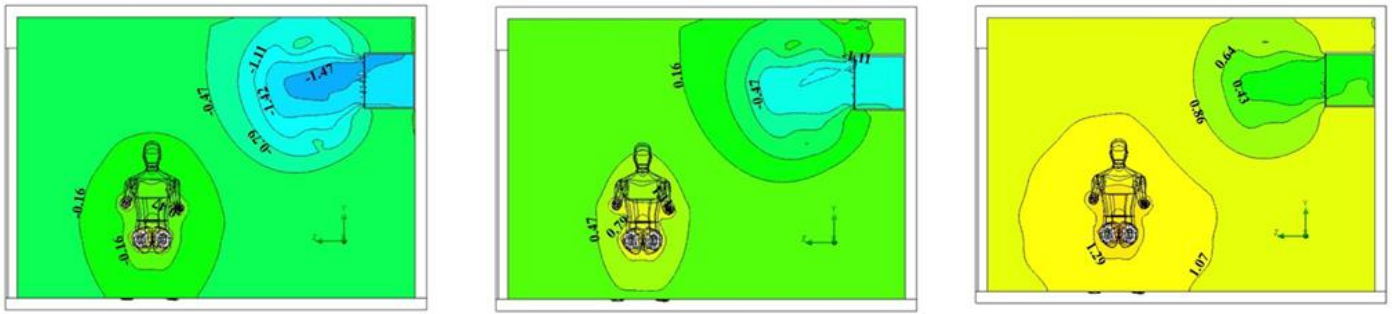

PPD
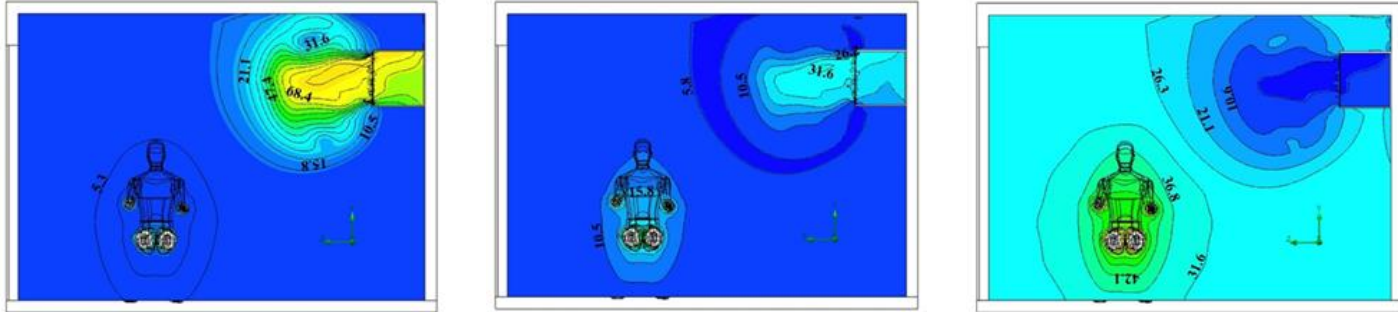

The PMV value has a range of 3.0 to be -3.0 , corresponding to the hot to cold thermal conditions. The result PMV shows that non-occupied is higher than occupied. Meanwhile, supply operative temperature $21^{\circ} \mathrm{C}$ and $26^{\circ} \mathrm{C}$ are slightly warm. Supply operative temperature at the $23^{\circ} \mathrm{C}$ indicates that the PMV is comfortable. Comparison of the finding states that air room temperature setting effect in $23^{\circ} \mathrm{C}$ is comfort than others. The value of PMV in a room temperature setting $23^{\circ} \mathrm{C}$ is 0.79 near the skin of an occupant. The PMV value near the human body is higher than the surrounding. Since the radiant temperature is a result of the radiation exchanges between the surfaces and the human body, its value depends on the complex interaction of these factors. 
PPD is the reflection from PMV. PPD is aimed to predict how many people feel uncomfortable due to a particular thermal condition in a room. The supply operative temperature at the $23{ }^{\circ} \mathrm{C}$ shows that PPD is lower than $20 \%$, this result indicates that $80 \%$ are satisfied with the environment.

Thermal discomfort rapidly increases when increasing operative temperature up to $26{ }^{\circ} \mathrm{C}$ compared to temperatures above $26^{\circ} \mathrm{C}$. However, thermal comfort vote evenly increases around both sides of neutral thermal conditions when changing a warmer or cooler thermal environment to neutral. Body temperature that stimulates physiological and behavioural thermoregulatory follows occupant thermal sensation and discomfort. Behavioural adaptation provides long-term thermoregulation, while physiological responses give a short-term solution.

\section{Conclusions}

In this study, the CFD simulation approach to determine the thermal environment and PMV values with an air conditioning system. By analyzing the simulation results between non-occupied and occupied space, the assessment of the thermal comfort of the office environment is performed based on the PMV model. The study found that operative temperature at the $23^{\circ} \mathrm{C}$ indicates that the PMV is comfortable. The value of PMV in a room temperature setting $23{ }^{\circ} \mathrm{C}$ is 0.79 near the skin of an occupant.

\section{Acknowledgement}

The authors would like to acknowledge the assistance or encouragement from National Institute of Occupational Safety and Health, Malaysia (NIOSH) by providing technical and financial support to Universiti Malaysia Kelantan (UMK) in conducting this research.

\section{References}

[1] Hamadache, M., Mouli, M., Nasr-eddine, B., Benosman, A.S., Dif, F., Chaib, O., and Madjid, B.H. "Use pf pozzolanic mortars for the thermal comfort of buildings." Journal of Advanced Research in Materials Science 34, no. 1 (2017): 1-7.

[2] Nikolina Pivac, and Sandro Nizetic. "Thermal comfort in office buildings: General issues and challenges." In 24th International Symposium On Heating, Refrigerating And Air Conditioning, (2017).

[3] Robinson D. "Some trends and research needs in energy and comfort prediction." In Proceedings of the Conference on Comfort and Energy Use in Buildings - Getting Them Right, (2006).

[4] Hensen, Jan LM. "Literature review on thermal comfort in transient conditions." Building and Environment 25, no. 4 (1990): 309-316. https://doi.org/10.1016/0360-1323(90)90004-B

[5] Djongyang, Noël, René Tchinda, and Donatien Njomo. "Thermal comfort: A review paper." Renewable and sustainable energy reviews 14, no. 9 (2010): 2626-2640. https://doi.org/10.1016/j.rser.2010.07.040

[6] Lin, Zhongping, and Shiming Deng. "A study on the thermal comfort in sleeping environments in the subtropicsMeasuring the total insulation values for the bedding systems commonly used in the subtropics." Building and Environment 43, no. 5 (2008): 905-916. https://doi.org/10.1016/i.buildenv.2006.11.026

[7] Cena, K., and J. A. Clark. "Physics, physiology and psychology." In Studies in environmental science, vol. 10, pp. $271-$ 283. Elsevier, 1981. https://doi.org/10.1016/S0166-1116(08)71094-X

[8] Fanger, Poul O. "Thermal comfort. Analysis and applications in environmental engineering." Thermal comfort. Analysis and applications in environmental engineering. (1970).

[9] Nielsen, Peter V. "Fifty years of CFD for room air distribution." Building and Environment 91 (2015): 78-90. https://doi.org/10.1016/j.buildenv.2015.02.035

[10] Parson, K. (2003). Human thermal environments: The effects of hot, moderate and cold environments of human health, comfort and performance. 2nd ed. London: Taylor \& Francis.

[11] Moss, Keith. Heat and mass transfer in building services design. Routledge, 2002.

[12] Standard, I. S. O. 7726 (1998) "Ergonomics of the thermal environment-Instruments for measuring physical quantities." International Organization for Standardization, Geneva, Switzerland.

[13] ASHRAE, ASHRAE Standard, and A. S. H. R. A. E. Standard. "55, Thermal environmental conditions for human occupancy." (2013). 
[14] Riachi, Youssef, and Denis Clodic. "A numerical model for simulating thermal comfort prediction in public transportation buses." International Journal of Environmental Protection and Policy 2, no. 1 (2014): 1-8. https://doi.org/10.11648/i.ijepp.20140201.11

[15] Nielsen, Peter Vilhelm. "Computational fluid dynamics and room air movement." Indoor air 14, no. Supplement 7 (2004): 134-143. https://doi.org/10.1111/j.1600-0668.2004.00282.x

[16] Yuan, X., Chen, Q.Y., Glicksman, L. R., Hu, Y., and Yang, X. "Measurements and computations of room airflow with displacement ventilation." ASHRAE Transactions 1, (1999): 105-340.

[17] Ismail, Mohd Azmi, and Mohd Sabri Che Jamil. "CFD HVAC Study of Modular Badminton Hall." CFD Letters 12, no. 7 (2020): 90-99. https://doi.org/10.37934/cfdl.12.7.9099

[18] Bulus, Markus, Lim Yaik-Wah, and Malsiah Hamid. "A study on the microclimatic performance of courtyard and non-courtyard residential buildings in hot-arid climate." Studies 9, no. 1 (2017): 1-13.

[19] Goldman, Ralph F. "Environmental ergonomics: Whence what wither." In Proceeding of the 11th International Conference on Environmental Ergonomics, Ystad, Sweden, pp. 39-47. 2005.

[20] Gagge, A.P., Stolwijk, J.A.J., and Nishi, Y. "The prediction of thermal comfort when thermal equilibrium is maintained by sweating." ASHRAE Transaction 75, (1969): 108-125.

[21] Strigo, Irina A., Franco Carli, and M. Catherine Bushnell. "Effect of ambient temperature on human pain and temperature perception." The Journal of the American Society of Anesthesiologists 92, no. 3 (2000): 699-707. https://doi.org/10.1097/00000542-200003000-00014

[22] Tanabe, Shin-ichi, Naoe Nishihara, and Masaoki Haneda. "Indoor temperature, productivity, and fatigue in office tasks." HVAC\&R Research 13, no. 4 (2007): 623-633. https://doi.org/10.1080/10789669.2007.10390975

[23] Catalina, Tiberiu, Joseph Virgone, and Frederic Kuznik. "Evaluation of thermal comfort using combined CFD and experimentation study in a test room equipped with a cooling ceiling." Building and environment 44, no. 8 (2009): 1740-1750. https://doi.org/10.1016/i.buildenv.2008.11.015 